\title{
Scientific Civilization and Cultural Crisis
}

\author{
Susanne K. LANGER \\ Connecticut College, New London, Connecticut
}

Every human life has an undercurrent of feeling that is peculiar to it. Each individual expresses this continuous pattern of feeling in what we call his "personality", reflected in behavior, speech, voice, and even physical bearing (stance and walk) as his individual style. On a larger scale, every human society has its undercurrent of feeling which is not individual, but general. Every person shares in it to some degree, and develops his own life of feeling within the frame of the style prevailing in his country and nis time.

Almost everywhere in the world today, the undercurrent of feeling is confused, uncertain, strained. There is much pride in it, but under the pride, fear; a great faith in science, and at the same time an irrationalism which betrays the shakiness of such faith; a growing sense of world-society, human rights, and the equal dignity of all mankind, and yet a prevailing hostility and jealousy that makes the world's political pattern, a protracted "cold war", in which every society eventually becomes involved. The basic feeling of most people today seems to be one of deep confusion in morals, aims, values, beliefs and motives.

The reason for all this emotional instability is not hard to find. Our generation has seen the greatest, most spectacular change of the human scene that has ever been recorded in history. It started with the so-called "industrial revolution" in Europe-the invention of power-driven machines to do the work which hands had always done, which led to mass production of goods. Mass production had the most dramatic effects on European civilization, making it boom into an entirely new way of life, and spread the economy and the political sway of Europe, briefly at least, over oceans and continents, especially westward to America, so that today the two American continuents are European in language and largely in population. When I speak of "modern civilization", therefore, I mean this civilization which has emanated from Europe, and found little to stop it from establishing itself first in America, and gradually throughout the world. Whatever it found it usually swamped and sunk, as past civilizations undoubtedly did in their day.

It is only rather recently that we are realizing what it has destroyed, and also the very grave fact that in its advance it is still destroying many things of undoubted and irreplaceable value; social orders of rank and status built up by a long national or local history, religious faith and its institutions, arts supported by solid and good traditions, ways of life in which people have long felt secure and useful. Such losses are not to be taken lightly.

There is no denying that the spearhead of this ruthless social revolution is something we all-at least in our present gathered company-honor and desire: Science. Science is the source and the pacemaker of this modern civilization which 
is sweeping away a whole world of cultural values. It is with good reason that we are meeting here to discuss the role of science in civilization; I would like to carry the issue a little further, and talk about the effect of this scientific civilization on human culture throghout the contemporary world. For it is not only in countries on which it has impinged suddenly and dramatically, but also in the countries of its origin-in Europe and America-that the technological revolution, with its entirely new mental and material standards, has deeply disturbed local and even national cultures.

This observation has a certain air of paradox how can civilization kill culture? Are not civilization and culture the same thing?

Wherever we encounter a paradox, we may look for a philosophical problemthat is, for a problem of meaning. Philosophy is the systematic study of meanings. Paradoxes are engendered by inexact or incomplete definitions, and a closer study of the concepts involved in them usually removes the paradoxes and reveals interesting distinctions among closely related processes and conditions instead. So the question which confronts us is essentially what we mean by culture and what by civilization. A more precise understanding of these two terms may serve to explain how, despite their intimate connection, a great strain may arise between a rapidly growing civilization and cultural values.

That civilization and culture are not the same thing is evident in the fact that there may be savage or civilized cultures. "Savage civilization", however, is a contradiction in terms.

A culture is the symbolic expression of developed habitual ways of feeling. By "feeling" I do not mean particularly pleasure and displeasure, to which many psychologists limit the word, nor just emotion and sensation, but everything that can be felt. We feel such elusive things as rhythms of attention and the strain of thought, bodily relaxation or tension that cannot be reduced to any particular sensation, attitudes of mind, the general activity of our imagination, confidence in the goodness of life or fundamental annoyance, boredom, cynicism, or again the countless modes of humor. Humor is one of the most individual marks of a people. All such phenomena of sensibility and general emotivity I am subsuming here under the word "feeling", as well as the distinct emotions. By ways of feeling I mean the degree to which feelings are apt to go, their persistence or transcience, the quickness of various responses, and their directedness to certain events rather than others.

Culture is the expression of this characteristic pattern of feeling, which sets one people off from another, in the pattern of their actions and the things involved in their actions-that is, specifically their things. Acts are generally purposive, and things useful, i.e. serving purposes; but both acts and artifacts go beyond practical needs in that they take on formal character, which is not efficacious but expressive. Human movements are not only motivated actions, but also gestures; human objects-from toothpicks to houses, cars, ships-have not only uses, but also style. The element of gesture in our actions is their gradual unconscious, formalization or sometime their deliberate and conscious formalization. This is most pronounced and detailed in ritual religious, military, academic, or purly festive; 
especially, of course, religious which is often quite intentionally symbolic of personal attitudes and aided by more permanent symbols, cult objects and images. Yet ritual is by no means the whole field of formalized action; some gestic value accrues to practically all social behavior as propriety, taste, good speech or coarse speech, good or bad manners, conformity or departure from unstated but familiar norms.

Such objective formal chammels of personal expression are our social heritage ; and as they lend our feelings and attitudes expression they also shape and establish them. They are the public influences which shape our private lives to fit our culture, and guarantee the continuity of vital feeling that unifies a natural community. Morality, custom and religion are, therefor, essentially conservative; and if they are left unshaken for very long periods they always harbor the danger of becoming ossified so feeling is reduced and devitalized in their narrowing channels. A growing culture requires departure, change, novelty in expressive forms-in language and ideas, visible objects, ways of doing things. There has to be a creative advance at fairly brief intervals if not all the time. Pioneering is the work of individuals; and a culture is doomed if it does not produce great nonconformists, who break the inherited moulds of expression by the force of their own new ideas which cut a channel for new elements of feeling and carve out a frame for new attitudes and moral sentiments.

Such personal innovations, however, may also be handed down from the very great to lesser men, or to younger people of genius as a cultural legacy. Culture is the entire treasure of achievement in a society. Its advance is somewhat like organic growth, slow, cumulative, changing yet self-identical.

Civilization is a somewhat different phenomenon. It is always a product of a high culture; but instead of being the symbolic aspect of behavior civilization is the pattern of the practical implementation of life. Practical-not necessarily physical; such arrangements as contracts, liabilities, legal regulations (e.g. traffic rules) are not physical instruments, but they are purely symbolic-pieces of paper, oyster-shell, metal or what not. But their aim is to facilitate the conduct of life.

Civilization, as the word implies, comes with the rise of cities. It is essentially a product of city life, and spreads from urban centers to the country. As long as a population lives directly on the land, each family finds or raises its own food, builds its own domicile and hands it on from one generation to another, public decisions are made by direct discussion, vote, declaration, command, or whatever be the practiced, goods are exchanged directly between interested parties. Custom usually suffices to determine people's duties and rights, and judges rely on it in deciding cases of wrong-doing or conflicts of interests. But when people cluster together in cities this ancient pattern breaks down. They can no longer hunt or raise their own food; the countryside has to supply it, day by day. They cannot offer goods in exchange for it, because they have nothing to offer that the foodraisers or gatherers require day by day, so a medium of exchange becomes necessary: money. With money, commerce becomes too complicated to be conducted on a basis of customary practices; besides, people in cities are often gathered from different communities, with various customs. This makes statute law necessary. 
An important cultural contribution of civic life is the close contact of people with each other, which steps up the exchange of ideas, the chance for each individual to learn things beyond his experience and ancestral background, the ferment of novelty contrasting with the quiet repetitiousness of country life. There is a change in mentality. Also, the city provides a goal of travel ; communication and movement assume a new importance. Everything tends toward the historic phenomenon we call "civilization"-the practical organization of life, public and private.

The seeds of civilization are in every culture, but it is city life that brings them to fruition. Like every process of fruition, civilization strains and drains the life which engenders and supports it-the culture which reaches its height in this development. Civilized life establishes a new balance between conservative and progressive elements, and tips the scales of feeling toward the venturesome, personalistic pole and away from piety and decorum. Such a shift of balance does not take place, of course, without flagrant exhibits of complete imbalance-lives culturally lost, degenerated, the familiar "criminal elements" and irresponsible drifters of every big city in the world.

This in itself, however, would probably not throw a great and prosperous culture into crisis; even the growing adventurousness of urban mentality, which leads the community to agression, wars of conquest, organized command, perhaps wide-flung empire, need not be fundamentally disturbing. Cultures have been built around war, and expressed themselves in heroic feats and triumphs and trophies. The danger of civilization to cultural life, more acute in our own world than in any previous era, is something less awful-looking, but really more serious. It has changed the character and the very function of war itself.

It is simply the fact that civilization can be transplanted, and live apart from its cultural roots. It can be grafted on other cultures and thrive on them. The products of civilization are devices-things, which can be carried to other places, techniques, which can be learned. Every invention, every process, wherever it may originate, today spreads over the whole world, leaving its cultural foundations behind, and impinges on the lives of people for whom it has no familiar form, no associations, no relations to other products or acts-nothing but usefulness. Finally civilization as a whole descends like an iron griel to crush the heritage of feeling and faith and the beauty of life.

Civilization-the practical structure of life-is like an outline tracing of the culture that begot it. As long as an outline lies on the painting from which it is made it takes special attention to abstract it; but moved away it appears as a stark and empty form, and imposed on another painting it makes for confusion. Our modern technology, transferred to practically all countries in the world, has caused civilization everywhere to follow its lines, and to change the conduct of life so radically that actuality and tradition seem to have no contact with each other. Even religious practices become untenable in the new practical frame; and with any failure of religious support, individuals tend to lose their emotional and moral stability. The community of feeling disintegrates when institutions lose their sacredness and seem merely old-fashioned, not venerable.

It is easy enough to understand why a civilization engendered by one localized 
and rather young culture like that of Europe should confuse the rest of the world; but why does it confuse and challenge the society that gave it birth? We all feel the same insecurity in the face of our miraculous technological progress which seems to race faster and faster toward complete control of the waters and fires on earth, the hidden powers of chemicals in the earth, the forces of light, air-pressure, and the rotation of the globe itself, and even toward the conquest of interstellar space.

The fact is, I think, that scientific production has outrun our imagination, and the change in our civilization-in the practical means and techniques of life-has advanced with a gathered momentum of its own and outstripped the advance of our thinking. Our technological civilization, consequently, seems to overtake and overwhelm us as though it were something foreign coming in upon us; it makes all our traditional institutions seem inadequate, so we tend to abandon them. State religion, marriage, paternal authority, deference to the aged, piety toward the dead, holiness and rank and royalty-all these ancient values have lost their inviolable status and need to be defended against the iconolastic "modern spirit". Sometimes, for all the defenses that the older generation can put up for them, a younger generation sweeps them away as relics of a superstitious, slavish, uncivilized past. But with them it sweeps away its own social symbols and the materials of its own world orientation; then personal life suddenly feels empty, and the civilization that shatters its spiritual comforts in the name of practical improvements seems to have come upon it like a superimposed power from outside.

This is, I think, an inevitable transition which really marks one of the great crises in human history - the final emergence of world society from the long ages of self-sufficient cultural groups. For science, which is certainly the keynote of our era, is international. It is a human achievement, not a national one. The civilization which is sweeping the whole world, though it is expressed mainly in commerce and new kinds of industry, is a product of science. We are in a socially anomolous state between a world populated by societies with tribal religions and interests, and a world of global industrial organization, populated by a society with global interests but no symbols to express them, no religion to support the individual in this vast new theatre of life.

Such disharmonies of growth are well known to every naturalist; and what happen in biological evolution can happen in psychological and social evolution, too. That strange emergence of new forms which my late friend and revered teachor, Alfred North Whitehead, called "the creative advance of nature", is not an orderly process. It is full of irregularities. According to the fossil rocord, some animals like the horse in attaining great body size came near to extinction before some other trait-the developmont of the brain, for instance, or of feet to bear tho added weight-caught up with the sudden increase. Many other species have had their critical phases, when in their continuation of the development of society there seems to be a similar unevenness, making for excess powers and cultural lags. When such transitional disproportions occur, strains are set up in the social organism which only time can even out. A new culture is probably in the making, which will catch up with the changed human environment that our runaway, free- 
wheeling civilization has visited on us. But one cannot forco the emergence of a real culture. It begins when imagination catches fire, and objects and actions become life symbols, and the new life-symbols become motifs of art. Art, which formulates and fixes human ways of feeling, is always the spearhead of a new culture; for culture is the objective record of developed feeling.

We will have to go way beyond what is now known as scientific thought, liberating a great disciplined imagination and encompassing subjects like mind, feeling, animal life, and values that mean something in a stellar universe.

What really fulfils and establishes a culture, however, is not art, but something that follows - the deeply and tacitly felt life of overt action, institutions, ways of living, things produced-Philosophy, law, exploration, martial virtues, religion-all have characterized various cultures in the past. We do not know what the driving force and the substance of the next cultural epoch will be, but I suspect that-as so often in narure-the same development which is breaking the old frame of our thinking will fashion the new one; namely, the development of science. My suspicion rests in several facts. One I just mentioned : that-as Pfluger said-" the cause of the need is the cause of the fulfilment of the need." The destructive force which shatters so many old cultures is really constructive of the new; the upheavals in the world are transitional functions. Another is the universal, global character of science. A culture that can embrace a worldwide civilization will probably by a global culture, encompassing all humanity. At present, scientific thinking is the only one of our great and prevailing activities which is universal in fact as well as in principle. We already claim the universality of art, and gradually come to appreciate other people's art, but it still starts by being exotic and often remains so even if we know and love it, Science is not native or exotic; it belongs to humanity and is the same wherever it is found. Only it is not likely to beget a culture unless, and until, a truly universal artistic imagination catches fire from its torch and serves without deliberate intent, to give shape to a new feeling, such as generally initiates a new epoch of society. Then the intellectual growth of science will have a vanguard to follow up and a "line of growth" to establish.

This growth is not likely to make recognizable progress in our own days, but that does not mean that no progress is going on. The great movements of society, the characteristic achievements of whole ages, do not gather force and form quickly. A scientific mentality capable of engendering a world culture will have to go far beyond what we call by its name today; it will have to liberate and yet discipline a great imagination, encompass such subjects as mind, growth, language and history, and produce social concepts that have meaning for a humanity which inhabits the whole earth and reaches for other stars. That is no five-year plan; it is no plan at all, but will happen or not happen without our resolutions to have it thus or otherwise. But something has to happen, of course, to break the tensions that are still building up today. There are signs of it already, and the youngest of us may live to see the beginnings, probably in one or another of the arts, of a really new feeling, destined to be the spearhead of a culture which will catch up with our runaway technological civilization, and overcome the out- 
ward violence and inward uncertainty which is the price or our first truly international possession-scientific thought. 